\title{
Proposal for optimization of a pull / push process follow-up of flexible packaging in the extrusion area
}

\author{
Adriana Lima Lindoso ${ }^{1}$, José Roberto Lira P. Júnior ${ }^{2}$, Luiz Felipe de Araújo Costa ${ }^{3}$, \\ Mauro Cesar Aparício de Souza ${ }^{4}$, David Barbosa de Alencar ${ }^{5}$, Antonio Estanislau Sanches ${ }^{6}$ \\ 1,2,3,4 Centro Universitário FAMETRO - Manaus-AM. \\ ${ }^{5}$ Instituto de Tecnologia Galileo da Amazônia - Manaus-AM. \\ ${ }^{6}$ Universidade do Estado do Amazonas - Manaus-AM.
}

Email: adriana.lindoso53@gmail.com, robertojunior72@gmail.com, luizfelipe_am@hotmail.com, mcas1691@gmail.com, david002870@ hotmail.com, novo.sanches@gmail.com

Received: December $30^{\text {th }}, 2018$

Accepted: January $10^{\text {th }}, 2019$

Published: March $31^{\text {th }}, 2019$

Copyright (C2016 by authors and Institute of Technology Galileo of Amazon (ITEGAM).

This work is licensed under the Creative Commons Attribution International

License (CC BY 4.0).

http://creativecommons.org/licenses/by/4.0/

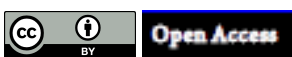

\section{ABSTRACT}

This work proposes the improvement in the process of the Extrusion sector of the company RS Embalagens for better use of its setup's. With the proposal to reduce the high loss rate, increase productivity and efficiency, reduce production costs in the extrusion process. As a result, increasing the productive capacity in this sector of the company, presenting improvements in the production process aiming at competitive growth in the market, avoiding raw material wastes, thus reducing the refuse index The globalization of the market has forced companies to seek continuous improvements within their production process, tending to reduce their waste so that they can improve their performance, thus reducing their setup, loss and cost indexes, which has attracted managers to more production with less The condition that the market establishes about products has been growing and companies must be able to compete and ready to face such demands from their customers.

Keywords: Productivity; Efficiency; Reduction of costs; Logistics;

\section{Proposta de otimização de um processo pull/push no seguimento de embalagens flexíveis na área de extrusão}

\section{RESUMO}

\begin{abstract}
Este trabalho propõe a melhoria no processo do setor de Extrusão da empresa RS Embalagens para melhor aproveitamento de seus setup's. Com a proposta de reduzir o alto índice de perdas, aumentar a produtividade e eficiência, reduzir os custos de produção no processo de extrusão. Como resultado, aumentando a capacidade produtiva neste setor da empresa, apresentando melhorias no processo produtivo visando o crescimento competitivo no mercado, evitando desperdícios da matéria-prima, assim reduzindo o índice de refugos. A globalização do mercado forçou as empresas na busca de melhorias continuas dentro do seu processo produtivo, tendendo a reduzir seus desperdícios para que consigam melhorar seus desempenhos reduzindo assim seus índices de setup, perda e custos o que tem atraído os gestores para produção mais com menos. A condição que o mercado estabelece sobre produtos vem crescendo e as empresas devem estar aptas a concorrer $\mathrm{e}$ prontas para enfrentar tais exigências de seus clientes.
\end{abstract}

Palavras-Chave: Produtividade; Eficiência; Redução de custos; Logística;

\section{INTRODUÇÃO}

Devido ao mercado globalizado as empresas focam em busca de melhorias continuas dentro do seu processo produtivo e tendem a reduzir seus desperdícios para que consiga melhorar seu desempenho reduzindo assim seus índices de setup, perda e custos o que tem atraído os gestores para produção mais com menos.

A condição que o mercado estabelece sobre produtos vem crescendo e as empresas devem estar aptas a concorrer e prontas para enfrentar tais exigências de seus clientes, pois muitos métodos são criados, implementados e adaptados aos sistemas atuais como ferramentas de controle com o objetivo 
de eliminar desperdícios e as atividades que não agregam valor ao produto e vê-se a urgência de um trabalho eficiente, de qualidade e que busque melhorias no processo produtivo, permitindo desta forma, um melhor desempenho.

Foi apresentado o índice de perda no processo de Extrusão da empresa RS Indústria e Comércio de Embalagens Eireli, localizada na cidade de Manaus/Am, que opera na fabricação de embalagens flexíveis.

A proposta deste trabalho é apresentar melhorias nos setup's do processo de extrusão de embalagens, visando o crescimento competitivo no mercado para melhor aproveitamento da matéria-prima utilizada, evitando desperdícios no processo e assim reduzindo o índice de refugos.

Tendo como passos à proposta de reduzir o alto índice de perdas do processo de extrusão, aumentar a produtividade e eficiência no processo de extrusão, reduzir os custos de produção no processo de extrusão, otimizando os setup's, como resultado, aumentando a capacidade produtiva neste setor da empresa.

\section{FUNDAMENTAÇÃO TEÓRICA}

\section{II.1 PRODUÇÃO PULL/PUSH - PUXADA / EMPURRADA}

A produção puxada tem a utilização de controlar as operações das fabricas sem o aproveitamento do estoque em curso, este modelo, diferencialmente da produção empurrada, a fluidez de materiais obtém expressiva prestígio. Aqui, a requisição fornecida pelo cliente é o start da produção, o comando de quê, quando e como produzir é limitado pela quantidade de produtos em estoque. Assim, o cálculo definido no processo capta a quantia de produtos vendidos aos clientes, e que, sem dúvida saíram do estoque.

Segundo [1], o controle de produção consiste basicamente em acompanhar a fabricação e compra dos itens planejados, para que os prazos sejam cumpridos e desta forma melhor atender seus clientes na data prevista solicitada pelos mesmos.

Tornou-se essencial um modelo produtivo mais adiantado e menos estático. A produção puxada aconteceu em uma época onde a qualidade começou a mostrar a compra de um produto e a procura deixou de ser ilimitada.

Esta associação dá-se com a aplicação do Sistema Kanbam em harmonia com o MRP, entre outros. Faz-se necessário salientar que é provável aplicar estas duas formas de sistema produtivo em um único sistema, com produção puxada e empurrada em pontos diferente do processo. Para [2], o sistema kanbam é um sistema de puxar a produção a partir da demanda, produzindo em cada estágio somente os itens e as quantidades necessárias no momento preciso.

Segundo [3], a atual situação do mercado tem a tendência de uma adaptação de uma economia pull a uma alternativa de economia push, devido a um aumento da concorrência, pois um aumento da oferta esta além da procura. A economia push representa um controle no mercado por parte do produtor que pode agrupar grandes quantidades de consumidores, esta abordagem procura satisfazer grande parte dos clientes. Na economia pull há a necessidade de identificar consumidores com diferentes necessidades e produtos feitos sob medida.

A produção empurrada é decretada a partir do desempenho do mercado. Este modelo, a produção da empresa inicia antes da existência da demanda pelo produto, ou seja, a produção necessita de uma ordem antecipadamente enviada, em geral oriunda de um sistema MRP. Após a entrega da ordem, é feita a produção em lotes de tamanho padrão. Aqui não está qualquer semelhança com a real procura dos clientes da empresa. Para [4], o sistema de produção é caracterizado, em sua entrada, por insumos, depois, passam pelo processo de transformação e finalmente irão sair como produtos, tendo os recursos a serem transformados, materiais, informações dos clientes, instalações, pessoal, recursos, transformações, planejamento, estratégias de produção e as prioridades competitivas.

Para [2], a tomada de decisão é o processo pelo qual são escolhidas as alternativas para as ações a serem tomadas como: planejamento, liderança, organização e controle das atividades ligadas à produção dentro das organizações.

Para [4], o MRP pode ser visto como uma técnica de programação dos itens que serão produzidos é como um sistema de controle de estoques, definindo a quantidade de cada item e quando essa quantidade deve estar disponível para produção. O planejamento especificado da produção inicia-se após o planejamento-mestre, que define as quantidades de produtos acabados que devem estar disponibilizados em datas específicas.

Para [5], os leads times deste tipo de produção devem ser conhecidos previamente, visto que as quantidades produzidas sem a ciência da real demanda necessitarão dos materiais fornecidos. A produção empurrada é conhecida como um sistema de inventário zero, mesmo este não sendo um fato real.

Este padrão de produção aconteceu no início da era industrial, onde a qualidade dos produtos não interessava muito, uma vez que havia uma demanda aproximadamente infinita em um mercado sem competição. O volume dos produtos produzidos para atender esta demanda era a única preocupação das indústrias.

\section{II.2 PRODUÇÃO DE FILMES PLÁSTICOS FLEXÍVEIS}

Conforme [6], a Gestão da produção é toda atividade empresarial e a própria intenção da existência de cada negócio. O propósito da empresa é basicamente produzir algo capaz de satisfazer as necessidades do mercado e do consumidor.

As atividades no setor de extrusão demandam melhoria na questão de perdas no processo quanto ao índice de aparas. Para produzir bens e serviços com baixo custo e que tenham valor e qualidade agregados, as empresas precisam trabalhar dentro de processos organizados [7].

O setor de extrusão seleciona as ordens de produção conforme as dimensões a serem produzidas pelo tamanho maior para depois ir reduzindo o balão para melhor aproveitamento no processo para que não haja muito desperdício e assim reduz o índice de refugo que é o maior problema na atual situação da produção. Para [1], o controle da produção consiste basicamente em acompanhar a fabricação e compra dos itens planejados, com o objetivo de que os prazos sejam cumpridos.

\section{II.3 PLANEJAMENTO E CONTROLE DO PROCESSO}

Para [4], um sistema de planejamento e controle da produção faz parte do sistema de informação produtiva, tendo como foco principal o gerenciamento de materiais, máquinas, mão de obra e fornecedores, o sistema operacional de produção é desenvolvido para atender as condições do mercado e às 
condições impostas pela estratégia da empresa que utiliza os sistemas. As atividades de planejamento e controle da produção exercem um papel fundamental no desempenho de uma organização, um sistema eficiente pode trazer vantagens competitivas substanciais à empresa no mercado que está inserida, a função produção trata da maneira pela qual as organizações produzem bens e prestam serviços.

Para [8], uma das definições para o planejamento é adequar, por meio de dimensões a utilização de recursos para atingir os objetivos dentro da demanda de produção, nessa fase é feito uma identificação dos produtos, procedimentos, tempos (horas estimadas) recursos humanos e materiais, é também importante que os operadores dominem suas atividades a serem envolvidas e executarem as tarefas de maneiras mais eficaz.

Para [9], o planejamento e controle da produção tem se mostrado a principal área que gera vantagens competitivas na manufatura em custo, qualidade, flexibilidade e desempenho de entregas, para projetar e operar este sistema de planejamento e controle é necessário compreender como os processos e recursos se articulam em torno dos objetivos da manufatura.

De acordo com [10], o planejamento e controle da produção é responsável pelo planejamento e controle do fluxo de materiais através do processo de produção, o planejamento da produção, a implementação, o controle e a administração do estoque são atividades conjuntas. Estoques na produção são utilizados para apoiá-las ou são o resultado da produção. Apenas se os itens comprados forem revendidos sem nenhum processo adicional pode a administração do estoque operar separadamente do planejamento e controle da produção, mesmo assim não é possível operar separadamente do compras.

\section{II.4 PRODUTIVIDADE}

O mercado de todos os segmentos tem característica comum, podemos informar uma competição provocada por seus concorrentes e de sua cadeia de suprimentos, com os prazos de entrega menores demandados pelos clientes e a qualidade dos produtos como pré-requisito fundamental para aquisição do produto. Em outras palavras, produtividade é obter a melhor relação entre volume produzido e recursos consumidos. Para [2], a produção tem responsabilidade por todas as atividades da organização que contribuem para uma produção efetiva de bens e serviços como responsabilidade direta, indireta e ampla.

Conforme [12], para melhorar a produtividade e a riqueza, uma empresa deve projetar sistemas eficazes e eficientes para produzir, deve administrar esses sistemas para fazer o melhor uso da força de trabalho, do capital e dos materiais e fazer isso por meio do planejamento e controle do fluxo de materiais que entram, percorrem e saem da produção, para isso existem três elementos no sistema de fluxo de materiais: suprimento, planejamento e controle da produção e distribuição física os mesmos são conectados e ligados uns aos outros.

A produtividade deve funcionar como um termômetro, tanto para auxiliar no diagnóstico de uma situação atual para acompanhar os efeitos de mudanças nas práticas gerenciais e na rotina de trabalho. Segundo [2], as medidas de produtividade são imprecisas porque algumas das grandezas envolvidas são de medição difícil, mas também porque vários conceitos envolvidos na definição são cercados de controvérsia.

Para [5], o planejamento de eficiência é feito em níveis, de acordo com o âmbito de planejamento pretendido. $\mathrm{O}$ planejamento de curto prazo é denominado de CRP - capacity requeriments planning, o mesmo é feito com base no plano de materiais detalhados, argumentando as sugestões do MRP de o que, quanto e quando produzir é o nível mais detalhado de planejamento de capacidade.

\section{II.5 FERRAMENTAS DA QUALIDADE}

As organizações, de uma forma geral, conscientizaram-se de que existe a necessidade de seus funcionários terem o conhecimento necessário para a realização de bens e serviços com qualidade. Perceberam também que esse conhecimento não será obtido sem que ela mesma o promova. Por outro lado, as pessoas também já se conscientizaram de que as organizações buscam profissionais que tenham o conhecimento de operações voltadas a qualidade.

A qualidade não é apenas mais uma opção das instituições, pois a concorrência utiliza metodologias e ferramentas com objetivos de extrair delas todo o potencial de melhoria e aceitação dos produtos. São ferramentas simples e muito eficazes que auxiliam o gestor na solução de problemas e ainda permitem o crescimento do ser humano em direção à melhoria da qualidade de vida, pois podem também ser utilizadas na esfera pessoal.

As principais ferramentas da qualidade utilizadas nesse trabalho foram: 5W2H: plano de ação e análise, Diagrama de Causa e Efeito, Diagrama de Pareto,

\section{METODOLOGIA}

Este trabalho, foi analisado in loco o processo de extrusão através de estágio supervisionado na empresa RS Indústria e Comércio de Embalagens Eireli. As ferramentas da qualidade utilizadas neste trabalho foram o Diagrama de Ishikawa onde mostra as problemáticas, o Diagrama de Pareto onde mostra a porcentagem das perdas no processo e a $5 \mathrm{~W} 2 \mathrm{H}$ para responder quando e como foi resolvido o problema.

\section{III.1 CARACTERIZAÇÃO DO ESTUDO}

A empresa estudada foi a RS Indústria e Comércio de Embalagens Eireli, localizada na Ave Itauba 1719 - Jorge Teixeira, na cidade de Manaus-AM. Fundada no ano de 1994, tem o objetivo de atender a demanda atual do mercado de sacos/ sacolas plásticas tendo em vista o alcance de critérios como qualidade, competitividade e responsabilidade ambiental, através de redução de perdas e desperdícios.

A unidade produtiva estudada possui um total de oitenta e cinco funcionários, sendo setenta e quatro deles atuantes no processo produtivo e onze na área administrativa. Atualmente, a organização oferece uma gama diversificada de sacos/sacolas plásticas, são elas: sacolas comuns para supermercado, sacolas impressas, sacos para capa fardo, entre outras. Sua missão "Oferecer soluções para industrialização e comercialização de embalagens plásticas em geral que atendam às expectativas das partes interessadas, através do comprometimento de todos os colaboradores com a melhoria contínua da qualidade dos processos e produtos, gerenciamento dos aspectos ambientais, requisitos legais de forma a prevenir a poluição e contribuir para o desenvolvimento sustentável". Sua visão "Manter o foco na gestão de processos de forma a consolidar a competitividade da RS Embalagens em seu segmento de mercado". 


\section{III.2 PROCEDIMENTOS EXPERIMENTAIS}

Para identificar as causas e garantir a organização e uma proposta eficiente foi necessário utilizar das seguintes ferramentas de gestão da qualidade: Gráfico de Pareto (análise das causas para um desenvolvimento da política de venda do produto), o Diagrama de Ishikawa que visou analisar a mão de obra, material, meio ambiente, medida, método e máquina, além do $5 \mathrm{~W} 2 \mathrm{H}$ (um método prático de gerenciamento das atividades de um projeto, nele analisa-se diversas causas para a obtenção da solução da problemática).

As atividades desenvolvidas no estágio supervisionado foram analisar as causas e perdas no processo, onde foi detectada uma perda de matéria-prima por conta da regulagem do balão para troca de ordem de produção, furo no balão, acerto de maquina, troca de ordem de produção, refile entre outros, foi verificado onde estão as perdas no processo que são as trocas de materiais que entram sem estar programados e com isso aumenta-se o índice de refugo, checou-se as ordens de produção se continha todas as informações para que os operadores seguissem a rotina e fizessem o acompanhamento da programação conforme solicitado e analisar se a mesma estava sendo executado de acordo com o programado. Verificando as formas de melhoria e aproveitamento no processo, foi detectado que quando não seguimos uma sequência do maior para o menor o índice de refugo aumenta bastante e com isso diminuímos nossa produtividade e aumentamos nosso custo.

\section{RESULTADOS}

As atividades no setor de extrusão demandam melhoria na questão de perdas no processo quanto ao índice de aparas.

Para alcançar a melhoria contínua no processo, foi analisado que é preciso seguir a programação das ordens de produção sempre considerando a sequência solicitada pelo gestor da área, seguindo do item maior para o menor para melhor aproveitamento de seus setup's. Para [6], não basta planejar, programar e executar os planos de produção é preciso monitorar e controlar o desempenho e os resultados do processo produtivo para se certificar de que estão ou não satisfatório.

Para reduzir o alto índice de perdas no processo é preciso a tomada de decisão partindo das possibilidades e/ou alternativas de produção quanto ao tamanho das bobinas a serem tiradas para melhor utilização no processo, pois quando se há flexibilidade em muitos momentos do processo é que faz a diferença, gerando assim a redução do alto índice das perdas. Segundo [2], a administração da produção é a atividade que se responsabiliza pela transformação de entradas e saídas gerenciando todas as atividades necessárias para que isso ocorra.

Quanto ao aumento de sua produtividade e eficiência sua tomada de decisão precisa estar alinhada com seus operadores para reduzir suas perdas, ajustando as espessuras determinadas pelas ordens de produção otimizando os produtos de acordo com seus dimensionais, quando é feito estes ajustes necessários o processo fica mais aperfeiçoado e com isto aumentamos nossa produtividade.

Seguindo nesta linha de pensamento de produzir com qualidade e eficiência, aumenta-se a produtividade e assim reduz os custos com os desperdícios de matéria-prima, pois o propósito da empresa é basicamente produzir algo capaz de satisfazer as necessidades do mercado e do consumidor.

A primeira ferramenta utilizada foi o Diagrama de Causas e efeitos que mostra de modo gráfico os problemas do processo e ajuda no controle da qualidade, abaixo as causas encontradas.

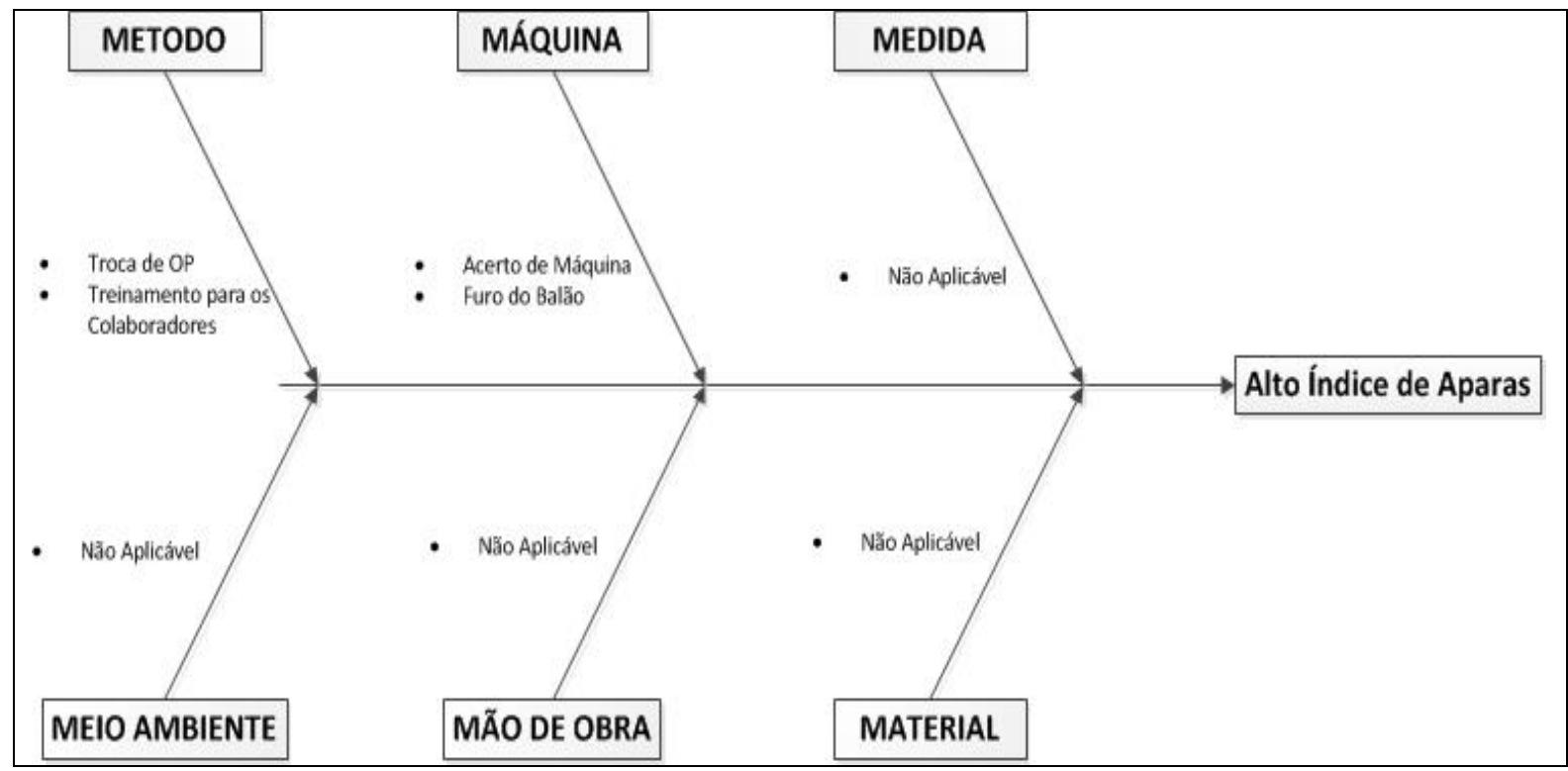

Figura 1: Diagrama de causa e efeito. Fonte: Autores, (2018).

As causas encontradas foram através de Relatório supervisionado na empresa junto ao Gestor da área onde foi observado o grande desperdícios de matéria-prima no setor de Extrusão quando é feito a troca de material, no furo do balão e no acerto de máquina.
Com os resultados obtidos por meio do Diagrama de causa e efeito, a segunda ferramenta utilizada para o plano de ação foi propor a solução da problemática utilizando o $5 \mathrm{~W} 2 \mathrm{H}$. 
Lindoso et al., ITEGAM-JETIA. Vol. 05, Nº 17, pp 43-48. March, 2019.

Tabela 1: aplicação do 5W2H para o alto índice de aparas.

\begin{tabular}{|c|c|c|c|c|c|c|c|}
\hline Causa Raiz & $\begin{array}{l}\text { O que deve ser } \\
\text { feito? }\end{array}$ & $\begin{array}{l}\text { Quem é o } \\
\text { responsável? }\end{array}$ & $\begin{array}{c}\text { Onde deve } \\
\text { ser feito? }\end{array}$ & $\begin{array}{l}\text { Quando } \\
\text { deve ser } \\
\text { feito? }\end{array}$ & $\begin{array}{l}\text { Por que é } \\
\text { necessário } \\
\text { fazer? }\end{array}$ & $\begin{array}{l}\text { Como será } \\
\text { feito }\end{array}$ & $\begin{array}{l}\text { Quanto vai } \\
\text { custar? }\end{array}$ \\
\hline $\begin{array}{l}\text { Fazer o acerto } \\
\text { de Máquina }\end{array}$ & $\begin{array}{c}\text { Ajustar } \\
\text { conforme os } \\
\text { tamanhos dos } \\
\text { produtos }\end{array}$ & Operadores & $\begin{array}{c}\text { No setor de } \\
\text { Extrusão }\end{array}$ & Imediato & $\begin{array}{c}\text { Para otimizar o } \\
\text { processo e } \\
\text { diminuir as } \\
\text { perdas }\end{array}$ & $\begin{array}{c}\text { Seguindo a } \\
\text { programação }\end{array}$ & $\mathrm{R} \$ 800,00$ \\
\hline $\begin{array}{l}\text { Evitar o furo } \\
\text { do Balão }\end{array}$ & $\begin{array}{l}\text { Evitar ao } \\
\text { máximo o furo } \\
\text { do balão }\end{array}$ & Operadores & $\begin{array}{c}\text { No setor de } \\
\text { Extrusão }\end{array}$ & Imediato & $\begin{array}{l}\text { Para diminuir } \\
\text { os desperdícios } \\
\text { de Matéria- } \\
\text { prima }\end{array}$ & $\begin{array}{c}\text { Seguindo a } \\
\text { programação }\end{array}$ & $\mathrm{R} \$ 800,00$ \\
\hline $\begin{array}{c}\text { Fazer as } \\
\text { trocas de OP's }\end{array}$ & $\begin{array}{l}\text { De acordo com } \\
\text { o dimensional } \\
\text { dos produtos }\end{array}$ & Lideres & $\begin{array}{c}\text { No setor de } \\
\text { Extrusão }\end{array}$ & Imediato & $\begin{array}{l}\text { Precisa trocar } \\
\text { de acordo com } \\
\text { o programado }\end{array}$ & $\begin{array}{c}\text { Seguindo a } \\
\text { programação }\end{array}$ & $\mathrm{R} \$ 800,00$ \\
\hline $\begin{array}{c}\text { Determinar } \\
\text { treinamento } \\
\text { para os } \\
\text { Colaboradores } \\
\end{array}$ & $\begin{array}{l}\text { Executar o } \\
\text { treinamento }\end{array}$ & $\begin{array}{c}\text { Empresa } \\
\text { especializada }\end{array}$ & $\begin{array}{c}\text { No setor de } \\
\text { Extrusão }\end{array}$ & Imediato & $\begin{array}{l}\text { Para melhor } \\
\text { aproveitamento } \\
\text { no processo }\end{array}$ & $\begin{array}{c}\text { Colocando em } \\
\text { prática o } \\
\text { aprendizado }\end{array}$ & $\mathrm{R} \$ 5.500,00$ \\
\hline TOTAL & & & & & & & $\mathrm{R} \$ 7.900,00$ \\
\hline
\end{tabular}

Fonte: Autores, (2018).

O gráfico de Pareto da figura 2 foi utilizado para identificar as três principais causas raízes encontradas de acordo com o Diagrama de Ishikawa, onde será feito trimestralmente os dados tabulados conforme abaixo:

Tabela 2: Tabela Causas por Trimestre.

\begin{tabular}{|c|c|c|c|c|}
\hline \multirow{2}{*}{ DESCRIÇÃO DAS CAUSAS } & \multicolumn{4}{|c|}{ FREQUÊNCIA } \\
\cline { 2 - 5 } & $1^{\circ}$ TRIMESTRE & $2^{\circ}$ TRIMESTRE & $3^{\circ}$ TRIMESTRE & $4^{\circ}$ TRIMESTRE \\
\hline & Qtde & Qtde & Qtde & Qtde \\
\hline TROCA DE OP & $26,08 \%$ & $27,63 \%$ & $29,72 \%$ & $52,45 \%$ \\
\hline ACERTO DE MÁQUINA & $63,01 \%$ & $61,12 \%$ & $59,91 \%$ & $10,62 \%$ \\
\hline FURO NO BALÃO & $10,91 \%$ & $11,25 \%$ & $10,38 \%$ & $19,86 \%$ \\
\hline & & & & $100 \%$ \\
\hline TOTAL & $100 \%$ & $100 \%$ & $100 \%$ & \\
\hline
\end{tabular}

Fonte: Autores, (2018).

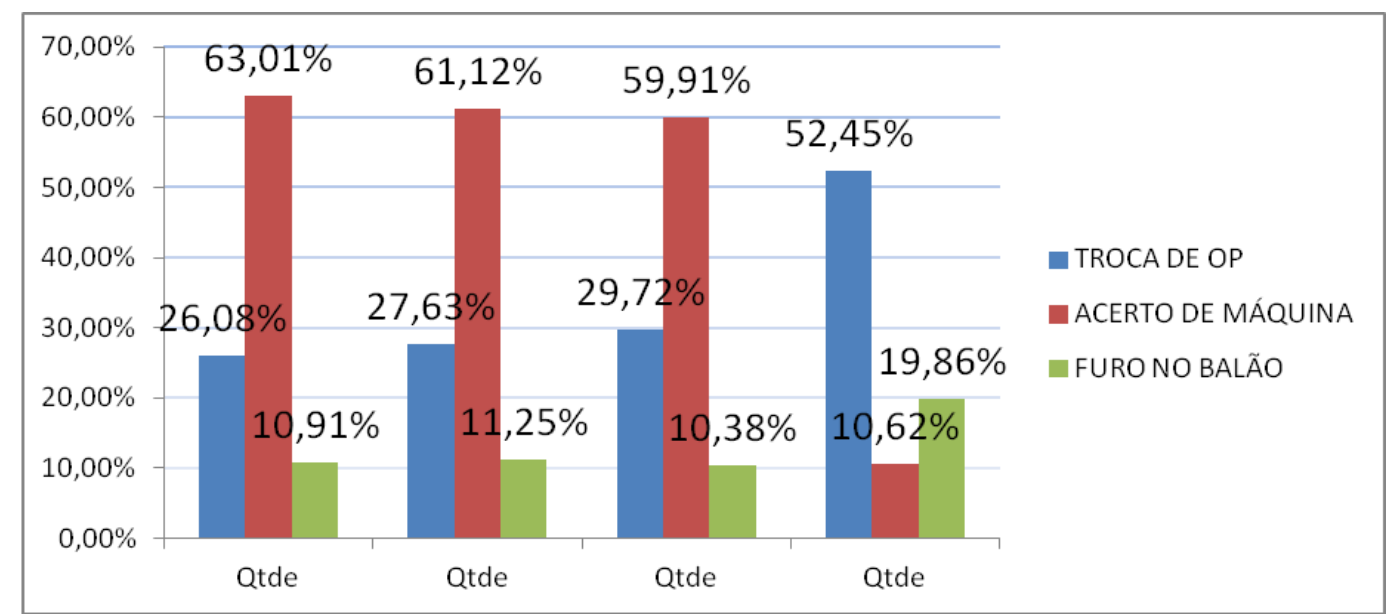

Figura 2: Gráfico de Pareto.

Fonte: Autores, (2018).

Conforme dados trimestral informado no gráfico de Pareto acima o maior gargalo de produção e desperdício de matéria-prima esta no acerto de máquina, por serem materiais de diferentes tamanhos e quantidades baixas para produzir. Mas se otimizarmos toda a entrega do mês e produzirmos de uma só vez, diminuímos este percentual gradativamente, mas não zeramos por se tratar de dimensões e clientes diferentes. A troca de ordem de produção é o segundo ponto a ser visto, pois seu índice de perda ocorre quando a troca é feita em pouco tempo de uma ordem para outra, pois quando as ordens são com pesos baixos a frequência de troca aumenta-se gradativamente. Quanto ao furo do balão ocorre quando 
acontece a falta de energia ou quando há vento forte próximo a máquina extrusora, para evitar este tipo de situação é colocado um plástico ao redor da máquina para proteger de ventos causados pela natureza, quanto a energia infelizmente não temos como prever este tipo de situação, mesmo tendo gerador não impede que isto aconteça.

\section{CONCLUSÕES E RECOMENDAÇÕES}

Observou-se que as aplicações de ferramentas específicas para aprimorar as rotinas de produção são de grande importância para se alcançar altos níveis de desempenho e facilidade com as atividades relacionadas a produção. A partir de uma análise crítica no processo de extrusão, por meio das ferramentas da qualidade que proporcionam maior credibilidade nas análises e na verificação dos principais defeitos nas operações, obtêm-se melhorias nas atividades desenvolvidas. Através deste relatório foi possível perceber que há um alto índice de perda no processo de extrusão e que este alto índice ocorre por não se seguir uma programação de acordo com o planejado pelo Gestor da área, por entrar pedidos críticos e com demandas baixas, fazendo assim aumentar os desperdícios de matéria-prima e aumentar as aparas. Com a nova proposta houve uma grande redução na quantidade de perdas e o tempo médio de atendimento diminuiu consideravelmente, com base nesta proposta de melhoria, visa-se a otimização do processo e com isto obtêm-se ganhos na produtividade de pelo menos $10 \%$. Portanto os objetivos do trabalho foram atingidos, visto que revelou que é possível melhorar a produção para que o setor de extrusão não seja o gargalo da produção. Houve algumas alterações quanto ao sequenciamento das ordens de produção para que reduza os setup's das máquinas programando pedidos totais dos clientes. Para a execução deste relatório, foi essencial reunir algumas informações sobre o processo, que serão de grande serventia para o departamento de programação e controle da produção, que poderá aplicá-las para realizar o sequenciamento da produção de aspecto mais eficaz. Recomenda-se o prosseguimento de um projeto pela empresa, para um sequenciamento da produção que seja incluído no software usado hoje para o gerenciamento da produção, o que traria grandes ganhos na produtividade das bobinas na extrusão.

\section{REFERÊNCIAS BIBLIOGRÁFICAS}

[1] Nogueira, Amarildo de Souza. Logística empresarial: uma visão local com pensamento globalizado. São Paulo: Atlas, 2012.

[2] Suzano, Márcio Alves. Administração da produção e operações com ênfase em logística - Rio de Janeiro: Interciência, 2013.

[3] Dias, João. Logística Global e Macro logística. Lisboa: Edições Síçabo, Lda, 2005

[4] Venanzi, Délvio. Silva, Orlando Roque da Silva. Gerenciamento da produção e operações. 1. ed. - Rio de Janeiro: LTC, 2013.

[5] Corrêa, Henrique Luiz. Gianesi, Irineu Gustavo Nogueira. Caon, Mauro. Planejamento, programação e controle da produção: MRPII/ERP: conceitos, uso e implantação: base no SAP, oracle applications e outros softwares integrados de gestão. 5. ed. - 8. reimpr. - São Paulo: Atlas, 2014.
[6] Penof, D. G.; Melo, C. E.; Ludovico, N. Gestão de produção e logística. São Paulo: Saraiva, 2013.

[7] Cruz, T. Sistemas, métodos \& processos. São Paulo: Atlas, 2003.

[8] Lobo, Renato Nogueirol. Gestão de Produção. São Paulo: Érica, 2010.

[9] Guerrini, Fábio Muller, Junior, Walther Azzolini, Belhot, Renato Vairo. Modelagem da organização: uma visão integrada. 1. ed. - Rio de Janeiro: Elsevier, 2014.

[10] Arnold, J. R. Tony; Tradução Celso Rimoli, Lenita R. Esteves. Administração de materiais: uma introdução. 1. ed. 10. reimpr. - São Paulo: Atlas, 2012 